\title{
An evaluation of risk factors affecting amputation in patients with diabetic foot infection
}

\author{
๑Handan Alay ${ }^{1}$, @Sinan Yllmaz ${ }^{2}$, @Fatma Kesmez Can ${ }^{1}$, ๑Mehmet Parlak ${ }^{1}$ \\ ${ }^{1}$ Department of Infectious Diseases and Clinical Microbiology, Faculty of Medicine, Ataturk University, Erzurum, Turkey \\ ${ }^{2}$ Department of Public Health, Faculty of Medicine, Ataturk University, Erzurum, Turkey
}

Cite this article as: Alay H, Yllmaz S, Kesmez Can F, Parlak M. An evaluation of risk factors affecting amputation in patients with diabetic foot infection. J Health Sci Med 2021; 4(1): 49-54.

\begin{abstract}
Introduction: Diabetic foot infections are one of the most common complications of diabetes and generally result in lower extremity amputations.

Aim: The purpose of this study is to investigate risk factors affecting amputation in patients diagnosed with diabetic foot ulcer. Material and Method: This prospective cohort study involved 137 patients diagnosed with diabetic foot infection in a university hospital diabetic foot clinic.

Results: The mean age of the participants was $60.5 \pm 10.1$ years, and $70.8 \%(n=97)$ were men. The majority of patients $(62.0 \%)$ were educated to elementary or middle school level, while $26.3 \%$ were illiterate. Mean duration of diabetes was $13.3 \pm 6.2$ years. Hypertension was present in $48.2 \%$ of patients, hypercholesterolemia in $31.4 \%$, cardiovascular disease (CVD) in $38 \%$, peripheral artery disease (PAD) in $21.2 \%$, peripheral venous insufficiency in $10.2 \%$, and polyneuropathy in $70.1 \%$, and $9.5 \%$ were receiving hemodialysis. According to the PEDIS classification, moderate foot ulcers were present in $60.6 \%$ of patients, mild ulcers in $34.3 \%$, and severe ulcers in 5.1\%. Forty-six percent of patients were diagnosed with osteomyelitis during follow-up. Amputation was present in $28.5 \%(\mathrm{n}=39)$ of the patients followed-up due to foot ulcers. PAD increased the risk of amputation 2.7-fold (95\% CI: 1.02-7.14), osteomyelitis 2.6-fold (95\% CI: 1.10-6.16), and repeated hospitalizations 5.9-fold (95\% CI: 2.25 15.33). Growth was observed in $72.6 \%$ of patients without amputation, $76.5 \%$ were polymicrobial, and $65.9 \%$ of antibiogram results were multidrug resistant. No significant difference was observed among the patients in terms of multidrug resistance $(\mathrm{p}=0.468)$.
\end{abstract}

Conclusion: PAD, osteomyelitis, and history of repeated hospitalizations are separate risk factors for amputation in patients with diabetic foot ulcers.

Keywords: Diabetic foot, amputation, risk factors, infection, multidrug resistance

\section{INTRODUCTION}

Diabetes mellitus (DM) is a metabolic disease affecting approximately 425 million individuals worldwide. Hyperglycemia is a condition caused by a problem in the effect and/or production of insulin (1). Diabetic foot ulcer (DFU) is one of the most common diabetic complications. The lifetime prevalence of DFU in diabetic patients is estimated at 19-34\% (2). DFU arising from peripheral neuropathy (PNP), peripheral vascular disease, and poor glycemic control results in lower extremity amputations (3). DFU causes amputation at different levels at a rate of approximately $20 \%$ (4). DFU therefore has an adverse impact on patients' quality of life and increases treatment costs. Several factors causing increased morbidity and mortality in diabetic

patients have been identified. These include the duration of the disease, coronary artery disease, smoking, male gender, diabetic nephropathy, and peripheral artery disease (PAD) (5). Diabetic foot infections are also associated with increased amputations rates, morbidity, and mortality $(6,7)$.

Polymicrobial infections can make healing of the ulcer less likely and can lead to amputation and death (8). The purpose of this study was to evaluate risk factors affecting amputation in the light of data obtained prospectively in patients under follow-up in our clinic with diagnoses of diabetic foot infection. 


\section{MATERIAL AND METHOD}

The study was carried out with the permission of Atarürk University Clinical Researches Ethics Committee (Permission granted: 07.05.2020, Decision no: 04-04, Ethics approval certificate: B.30.2.ATA.0.01.00/200). One hundred thirty-seven patients aged 18 or over, with type $2 \mathrm{DM}$ and hospitalized for treatment of foot ulcer in our clinic were included in this study that commenced in May 2019. This is a prospective study with a sample of 137 patients with DFU and infected. Patients were followed-up for one year. Repeat hospitalizations during the follow-up process were disregarded and considered as a single case.

Demographic data including age, sex, place of residence, and education level, and duration of disease, treatment received and presence of amputation, and comorbid conditions including hemodialysis, cardiovascular disease (CVD), hypercholesterolemia, hypertension $(\mathrm{HT})$, PAD, peripheral venous insufficiency (PVI), peripheral neuropathy (PNP), smoking, and osteomyelitis, tissue culture results, polymicrobial growth, and multidrug resistance (MDR) of growing agents were evaluated.

All open lesions on the feet of patients with diabetes were defined as ulcers and we hospitalized patients diagnosed with DFUs whose general condition was so poor that outpatient clinic-based treatments were not possible. All ulcers were analyzed according to the severity of infection using the PEDIS (Perfusion, Extent/size, Depth/tissue loss, Infection) classification (9). According to this classification, absence of signs and findings of infection is defined as "Grade 1". Local infection involving only the skin and subcutaneous tissue (rim of erythema around the ulcer of $0.5-2 \mathrm{~cm}$ ) is defined as "Grade 2". Involvement of structures extending deeper than the skin and subcutaneous tissue (abscess, osteomyelitis, septic arthritis, fasciitis) without systemic infection findings, and with a rim of erythema around the ulcer $>2 \mathrm{~cm}$ is defined as "Grade 3". The presence, in addition to local infection, of at least two inflammatory response syndrome markers (body temperature $>38^{\circ} \mathrm{C}$ or $<36^{\circ} \mathrm{C}$, heart rate $>90$ beats/min, respiratory rate $>20$ / min or $\mathrm{PaCO}_{2}<32 \mathrm{mmHg}$, or white cell count $>12,000$ or $4000 \mathrm{cell} / \mathrm{uL}$ or $\geq 10 \%$ band formation) is defined as "Grade 4".

Osteomyelitis was diagnosed via magnetic resonance imaging. Presence of PNP was evaluated on electromyography (EMG) test. Vascular evaluations were made by means of palpation of distal pulses, and using Doppler ultrasound. Cultures in which there was no bacterial growth were considered negative. Cultures that grew two or more different bacteria were considered polymicrobial. The fact that the factors isolated from patients were resistant to at least one of three or more antibiotic groups was defined as MDR (10). Amputations were defined as under-ankle amputations as minor, and above-ankle amputations as major amputations. $\mathrm{HbA}_{1 \mathrm{c}}$ levels were employed to assess patients' diabetic control. Laboratory values at time of presentation to the clinical were employed at statistical analysis

\section{Statistical Analysis}

Data analysis was performed on SPSS for Windows version 22 software (Statistical Package for the Social Sciences). Categorical variables were expressed as number and percentage, and numerical variables as mean plus standard deviation. Normality of distribution of numerical variables was investigated using the Kolmogorov Smirnov test, $\mathrm{z}$ values calculated for skewness and kurtosis, and charts/tables. The $t$ test was used to compare normally distributed numerical variables between the groups, the Mann Whitney $U$ test to compare non-normally distributed numerical variables between the groups, and the $\chi^{2}$ test to compare the distribution of categorical variables in the groups. Binary logistic regression analysis was applied to identify risk factors affecting amputation. Independent variables identified as significant at univariate regression analysis were included in the regression model. The backward LR method was used at regression analysis. $\mathrm{p}$ levels $<0.05$ were regarded as significant for all analyses.

\section{RESULTS}

The mean age of the 137 cases included in the study was $60.5 \pm 10.1$ years, and $70.8 \%(n=97)$ were men. Mean ages were $62.5 \pm 11.9$ years for women and $59.6 \pm 9.2 \mathrm{men}$, and the difference was not statistically significant $(\mathrm{p}=0.132)$. The majority of patients $(62.0 \%)$ were educated to elementary or middle school level, and $26.3 \%$ were illiterate.

Mean duration of diabetes was $13.3 \pm 6.2$ years. While $48.9 \%(\mathrm{n}=67)$ of patients were using insulin alone for DM, 37.2\% were using insulin together with oral hypoglycemic drugs. A history of smoking was present in $36.5 \%$ of patients, and $20.4 \%$ were still smokers.

Mean blood leukocyte count (WBC) at time of admission to the clinic was $9982.9 \pm 4172.8, \mathrm{C}$-reactive protein (CRP) $64.6 \pm 65.4 \mathrm{mg} / \mathrm{L}$, sedimentation rate $55.7 \pm 29.5 \mathrm{~mm} / \mathrm{h}$, $\mathrm{HbA}_{1 \mathrm{c}} 9.5 \pm 2.6 \mathrm{mg} / \mathrm{dL}$, and creatinine $1.4 \pm 1.5 \mathrm{mg} / \mathrm{dL}$.

HT was present in $48.2 \%$ of patients, hypercholesterolemia in $31.4 \%, \mathrm{CVD}$ in $38 \%$, PAD in $21.2 \%$, PVI in $10.2 \%$, and PNP in $70.1 \%$, and $9.5 \%$ were receiving hemodialysis. According to the PEDIS classification, "grade 3" foot ulcers were present in $60.6 \%$ of patients, "grade 2 " ulcers in $34.3 \%$, and "grade 4 " ulcers in $5.1 \%$. Forty-six percent 
of patients were diagnosed with osteomyelitis during follow-up. Amputation was present in $28.5 \%(n=39)$ of patients followed-up due to foot ulcers. 34 of the cases were minor and 5 were major amputation. No mortality occurred during the follow-up period.

Patients with amputation were compared with those without amputation. PAD was present in $21.2 \%(\mathrm{n}=29)$ of cases, and the distribution of amputations was significantly higher these patients than in those without PAD ( $\mathrm{p}=0.037)$. Osteomyelitis developed in $46.0 \%(\mathrm{n}=63)$ of patients, and the distribution of amputation was also higher among these patients $(p=0.004)$.

Growth was observed in $27.4 \%$ of tissue cultures in amputated patients and in $72.6 \%$ among non-amputated patients, of which $23.5 \%$ and $76.5 \%$, respectively, were polymicrobial. Growth in culture and polymicrobial culture results were similar among the amputated and non-amputated patients $(\mathrm{p}=0.518$, and $\mathrm{p}=0.462$, respectively). However, antibiogram results of $34.1 \%$ of amputated patients and $65.9 \%$ of non-amputated patients were reported as MDR (+), and no significant difference in MDR distributions was observed among the patients $(\mathrm{p}=0.468)$. The agents most commonly isolated from cultures were Staphylococcus spp. (36.7\%) in amputated patients and Escherichia spp. (35.3\%) in non-amputated patients.

Demographic characteristics of the patients with and without amputation, comorbid characteristics, a comparison of various laboratory parameters, and distributions of foot ulcers according to the PEDIS classification are shown in Table $\mathbf{1 .}$

Logistic regression analysis was applied in order to evaluate risk factors for amputation. Major and minor amputations were included in the regression model as a dependent variable. Risk factors identified as significant at univariate analysis were added to the multivariate regression model. PAD, osteomyelitis, and history of repeated hospitalizations were found to make a significant contribution to the final model obtained using the backward elimination method with presence of amputation as the dependent variable. PAD increased the risk of amputation 2.7-fold (95\% CI: 1.02-7.14), osteomyelitis 2.6-fold (95\% CI: 1.10-6.16), and repeated hospitalizations 5.9-fold (95\% CI: 2.25-15.33) (Table 2).

\begin{tabular}{|l|c|c|c|c|}
\hline \multicolumn{7}{|l|}{ Table 2. Logistic regression analysis results } \\
\hline Variable & Wald & OR & 95\% CI & p value \\
\hline Hemodialysis & 3.113 & 3.394 & $0.873-13.193$ & 0.078 \\
PAD & 3.977 & 2.695 & $1.017-7.142$ & 0.046 \\
Osteomyelitis & 4.800 & 2.611 & $1.106-6.163$ & 0.028 \\
Repeated hospitalization & 13.128 & 5.881 & $2.255-15.335$ & $<0.001$ \\
\hline R2 $=0.28$ (Nagelkerke). $\chi^{2}(5)=1.12$ (Hosmer\&Lemeshow) \\
\hline
\end{tabular}

\section{DISCUSSION}

Diabetic foot ulcer is a complication involving severe outcomes, such as psychosocial problems, the need for prolonged hospitalization for treatment, and amputation. Some recent studies have reported that DFU is an important independent predictor of mortality and frequently leads to lower extremity amputation $(11,12)$. It is of great importance to identify risk factors in order to prevent extremity losses in patients with DFUs. In the present study, PAD, osteomyelitis, and a history of repeated hospitalizations were identified as independent risk factors for amputation at logistic regression analysis.

The mean age of the patients undergoing amputation was 61. One population-based study reported an approximate mean age of 65 (13). While some studies have reported a significant effect of age on amputations others, including the present research, have reported no such effect $(14,15)$.

Sex was reported as a risk factor in Moon et al.'s study of risk factors for major amputation in DFU patients (16). Studies have also shown that major amputation rates in DFUs are significantly higher among men than in women $(17,18)$. In the present study, although the amputation rate was higher among male DFU patients, sex was not identified as a risk factor at regression analysis. Men are generally taller, and PNP is more common among men. In addition, joint mobility and the pressure to which the feet are exposed are also greater in men $(19,20)$. In contrast, women pay more attention to personal care, and engage in more active wound care (21). These factors may account for the higher prevalences of DFU and amputation among men.

Orneholm et al. reported a significant association between age and wound healing in patients with DFUs (22). Studies have also reported that advanced age and duration of diabetes exceeding 10 years increase the risk of mortality (23). On the other hand, it is also possible to encounter studies reporting that age is not a risk factor for amputation (16). The findings of the present study suggest that patient age and duration of diabetes are not risk factors for amputation ( $p>0.05)$.

Several studies have described weak glycemic control as a risk factor for amputation in diabetic patients (16, $24,25)$. In contrast to Selvin et al's study describing an increase in $\mathrm{HbA}_{1 \mathrm{c}}$ levels as increasing the risk of major amputation, Winkley et al. reported that low $\mathrm{HbA}_{1 \mathrm{c}}$ levels were associated with higher mortality $(26,27)$. $\mathrm{HbA}_{1 \mathrm{c}}$ was also not reported as a predictive factor for amputation in Cardoso et al.s study (28). Serum $\mathrm{HbA}_{1 \mathrm{c}}$ levels were also not identified as a risk factor for amputation in the present study. 


\begin{tabular}{|c|c|c|c|c|}
\hline Variables & & Amputated $(n=39)$ & Non-amputated $(\mathrm{n}=98)$ & p value \\
\hline Age (years) & & $60.7 \pm 11.6$ & $60.4 \pm 9.5$ & 0.845 \\
\hline \multirow{2}{*}{$\operatorname{Sex}[\mathrm{n}(\%)]$} & Female & $13(32.5)$ & $27(67.5)$ & \multirow{2}{*}{0.502} \\
\hline & Male & $26(26.8)$ & $71(73.2)$ & \\
\hline \multirow{4}{*}{ Education [n (\%)] } & Not literate & $15(41.7)$ & $21(58.3)$ & \multirow{3}{*}{0.068} \\
\hline & Elementary/middle school & $22(25.9)$ & $63(74.1)$ & \\
\hline & High school/university & $2(12.5)$ & $14(87.5)$ & \\
\hline & Duration of diagnosis (years) & $13.2 \pm 6.5$ & $13.3 \pm 6.2$ & 0.914 \\
\hline \multirow{3}{*}{ Diabetes treatment $[\mathrm{n}(\%)]$} & Insulin & $18(26.9)$ & 73.1 & \multirow{3}{*}{0.253} \\
\hline & Oral hypoglycemic drugs & $3(15.8)$ & 84.2 & \\
\hline & Insulin and oral hypoglycemic drugs & $18(35.3)$ & 64.7 & \\
\hline \multirow{2}{*}{ Smoking history [n (\%)] } & Yes & $14(28.0)$ & $36(72.0)$ & \multirow{2}{*}{0.815} \\
\hline & No & $26(29.9)$ & $61(70.1)$ & \\
\hline \multirow{2}{*}{ Hypertension [n (\%)] } & Yes & $21(31.8)$ & $45(68.2)$ & \multirow{2}{*}{0.515} \\
\hline & No & $19(26.8)$ & $52(73.2)$ & \\
\hline \multirow{2}{*}{ Hypercholesterolemia [n (\%)] } & Yes & $10(23.3)$ & $33(76.7)$ & \multirow{2}{*}{0.301} \\
\hline & No & $30(31.9)$ & $64(68.1)$ & \\
\hline \multirow{2}{*}{ Cardiovascular disease [n (\%)] } & Yes & $15(28.8)$ & $37(71.2)$ & \multirow{2}{*}{0.944} \\
\hline & No & $25(29.4)$ & $60(70.6)$ & \\
\hline \multirow{2}{*}{ Peripheral artery disease [n (\%)] } & Yes & $13(44.8)$ & $16(55.2)$ & \multirow{2}{*}{0.037} \\
\hline & No & $27(25.0)$ & $81(75.0)$ & \\
\hline \multirow{2}{*}{ Peripheral venous insufficiency [n (\%)] } & Yes & $4(28.6)$ & $10(71.4)$ & \multirow{2}{*}{0.957} \\
\hline & No & $36(29.3)$ & $87(70.7)$ & \\
\hline \multirow{2}{*}{ Peripheral neuropathy [n (\%)] } & Yes & $31(32.3)$ & $65(67.7)$ & \multirow{2}{*}{0.233} \\
\hline & No & $9(22.0)$ & $32(78.0)$ & \\
\hline Hemodialvsis [n (\%)] & Yes & $7(53.3)$ & $6(46.2)$ & 0.054 \\
\hline renociarysts [11 (\%)] & No & $33(26.6)$ & $91(73.4)$ & 0.034 \\
\hline & Yes & $26(41.3)$ & $37(58.7)$ & \\
\hline Usteomyelitis [n (\%)] & No & $14(18.9)$ & $60(81.1)$ & 0.004 \\
\hline & Grade 2 & $7(14.9)$ & $40(85.1)$ & \\
\hline PEDIS classification [n (\%)] & Grade 3 & $29(34.9)$ & $54(65.1)$ & 0.056 \\
\hline & Grade 4 & $3(42.9)$ & $4(57.1)$ & \\
\hline & WBC & $10345.4 \pm 4299.1$ & $9838.6 \pm 4135.1$ & 0.523 \\
\hline & Sedimentation $(\mathrm{mm} / \mathrm{h})$ & $62.7 \pm 22.3$ & $52.9 \pm 31.6$ & 0.043 \\
\hline & CRP & $75.5 \pm 74.4$ & $60.3 \pm 61.4$ & 0.317 \\
\hline & Creatinine (mg/dL) & $1.8 \pm 2.2$ & $1.3 \pm 1.1$ & 0.588 \\
\hline & $\mathrm{HbAlc1}(\mathrm{mg} / \mathrm{dL})$ & $9.7 \pm 2.8$ & $9.4 \pm 2.5$ & 0.901 \\
\hline Grouth in culture $\left[\mathrm{n}(0 /)^{*}\right]$ & Yes & $34(87.2)$ & $90(91.8)$ & 0.518 \\
\hline Grownin inc cuiture [11 (\%) ] & No & $5(12.8)$ & $8(8.2)$ & 0.510 \\
\hline Polymicrobial culture result [n $(\%) *]$ & Yes & $8(20.5)$ & $26(26.5)$ & 0.462 \\
\hline rorynicroviar cuiture resuil [in(\%) ] & No & $31(79.5)$ & $72(73.5)$ & \\
\hline Multinl drug recistonce [n $\left.(0 /)^{*}\right]$ & Yes & $14(48.3)$ & $27(40.3)$ & 0468 \\
\hline iviuitupi arug resistance $[\mathrm{n}(\%)]$ & No & $15(51.7)$ & $40(59.7)$ & 0.408 \\
\hline & Enterococcus spp & $2(5.9)$ & $8(8.9)$ & \\
\hline & Staphylococcus spp & $7(20.6)$ & $33(36.7)$ & \\
\hline & Streptococcus spp & $1(2.9)$ & $5(5.6)$ & \\
\hline & Acinetobacter spp & $2(5.9)$ & $9(10.0)$ & \\
\hline Pathogens orowing in culture $\left[\mathrm{n}(\%)^{*}\right]$ & Citrobacter spp & $3(8.8)$ & $5(5.6)$ & \\
\hline Patnogens growing in cuiture $[\mathrm{n}(\%)]$ & Escherichia spp & $12(35.3)$ & $17(18.9)$ & \\
\hline & Enterobacter spp & $2(5.9)$ & $3(3.3)$ & \\
\hline & Klebsiella spp & $1(2.9)$ & $6(6.7)$ & \\
\hline & Proteus spp & $3(8.8)$ & $3(3.3)$ & \\
\hline & Pseudomonas spp & $1(2.9)$ & $1(1.1)$ & \\
\hline
\end{tabular}


A low level of education can adversely effect patients possession of adequate information about diabetes and its complications, and also the prevention of such complications (28). No association was determined between patients' education levels and amputation status in the present study, and education did not emerge as a risk factor in progression to amputation.

Osteomyelitis was identified as a risk factor increasing progression to amputation 2.6-fold in patients with DFUs ( $\mathrm{p}=0.028)$. Namgoong et al. reported that ulcers with bone involvement were an important risk factor for major amputation (29). Based on the study findings, the treatment decision being taken in the early period appears to be very important in preventing the progression of DFUs and amputation.

Hypertension, PNP, nephropathy and dyslipidemia also appear among the risk factors for amputation in the literature $(29,30,31)$. However, no significant relationship between amputation and HT, hypercholesterolemia, CVD, PNP, or neuropathy was observed in the present study. The presence of PAD has been described as one of the important risk factors for amputation in diabetics $(29,32)$. In the present study, presence of PAD increased the risk of amputation 2.7 -fold $(\mathrm{p}=0.046)$.

Diabetic patients are generally hospitalized for treatment due to other comorbid diseases and foot ulcers. In the present study, a history of repeated hospitalization increased the risk of amputation 5.9-fold $(\mathrm{p}<0.001)$. While this study was planned as prospective single-center research involving only patients under follow-up by the infectious diseases clinic, the short follow-up period of one year represents its principal limitation. In addition, the effectiveness in terms of progression to amputation of multidisciplinary diabetic foot management could not be evaluated. We think that multi-center and multidisciplinary studies are now needed to assess risk factors for amputation in patients with DFUs.

The type of bacterium isolated from infected ulcers of diabetic feet was not identified as a risk factor for amputation in this study. The most commonly isolated bacteria in the amputated patient group were E. coli (35.39\%) and Staphylococcus spp. (20.6\%). In a study conducted in our country, it was reported that the most common bacteria isolated from diabetic wound infections are Staphyloccus aureus, group B hemolytic streptococci and Klebsiella spp. (33). In Cardoso et al.s study, the most commonly isolated micro-organisms in DFUs in patients with amputation and resulting in mortality were Acinetobacter spp. (33.3\%), Morganella spp. (33.3\%) and Proteus spp. (27.8\%). The type of bacterium isolated was reported not to constitute a risk factor associated with mortality (28). In another, retrospective, study, $65 \%$ of cases resulted in amputation, and the most common bacteria were Staphyloccus spp. (34).

Polymicrobial cultures may also occur in patients with DFUs, and this can delay the ulcer healing process (8). No polymicrobial culture dominance $(23.5 \%)$ was observed in amputated patients in this study, and polymicrobial culture was not identified as a risk factor for amputation. Polymicrobial growth is frequently present in patients with severe infection and prolonged DFUs. Knowing the microbiological etiology is an important factor in managing the treatment of DFUs.

Multidrug resistant infections are a significant and growing global problem. Resistant strains prolong patients' hospital stays and increase treatment costs (35). Although the prevalence of MDR was higher in our non-amputated patient group (65.9\%), there was no significant difference among the patients in terms of MDR distributions. Prolonged DFUs can result in repeated hospitalizations and multidrug resistant infections. Knowledge of antibiotic susceptibility and multidrug resistance status will be helpful to physicians in prescribing effective medications in the treatment of DFUs.

\section{CONCLUSION}

Peripheral artery disease, osteomyelitis, and a history of repeated hospitalizations emerged as risk factors for amputation in patients with DFUs. The identification of risk factors can serve as a useful guide to physicians in the management of such patients. The ability to control diabetic foot and its complications depends on the establishment of a multidisciplinary clinical team and the development of public health-based protection strategies.

\section{ETHICAL DECLARATIONS}

Ethics Committee Approval: The study was carried out with the permission of Atarürk University Clinical Researches Ethics Committee (Permission granted: 07.05.2020, Decision no: 04-04).

Informed Consent: All patients signed the free and informed consent form.

Referee Evaluation Process: Externally peer-reviewed.

Conflict of Interest Statement: The authors have no conflicts of interest to declare.

Financial Disclosure: The authors declared that this study has received no financial support. 
Author Contributions: All of the authors declare that they have all participated in the design, execution, and analysis of the paper, and that they have approved the final version.

\section{REFERENCES}

1. International Diabetes Federation, IDF Diabetes Atlas, International Diabetes Federation, Brussels, Belgium, 8th edition, 2017.

2. Zhang P, Lu J, Jing Y, Tang S, Zhu D, Bi Y. Global epidemiology of diabetic foot ulceration: a systematic review and meta-analysis. Ann Med 2017; 49: 106-16.

3. Apelqvist J, Larsson J. What is the most effective way to reduce incidence of amputation in the diabetic foot? Diabetes Metab Res Rev 2000; 16 Suppl 1: S75-S83.

4. Chronic Complications of Diabetes, Diabetes and Foot. National Diabetes Consensus Group. TURKDIAB Diabetes Diagnosis and Treatment Guideline. 2019; 121-30.

5. Brownrigg JRW, Griffin $M$, Hughes CO, et al. Influence of foot ulceration on cause-specific mortality in patients with diabetes mellitus. J Vasc Surg 2014; 60: 982-6.

6. Turhan V, Mutluoglu M, Acar A, et al. Increasing incidence of Gram-negative organisms in bacterial agents isolated from diabetic foot ulcers. J Infect Dev Ctries 2013; 7: 707-12.

7. Armstrong DG, Boulton AJM, Bus SA. Diabetic foot ulcers and their recurrence. N Engl J Med 2017; 376: 2367-75.

8. Spicler A, Hurwitz BL, Armstrong DG, Lipsky BA. Microbiology of diabetic foot infections: from Luis Pasteur to 'crime scene investigation'. BMC Med 2015; 13: 1-13.

9. The International Working Group on the Diabetic Foot. International consensus on diagnosing and treating the infected diabetic foot. $4^{\text {th }}$ International symposium on the diabetic foot. Noordwijkenhout-The Netherlans. 22-24 May 2003. Schaper NC. Diabetes Metab Res Rev 2004; 20: 90-5.

10. Magiorakos AP, Srinivasan A, Carey RB, et al. Multidrug-resistant, extensively drug-resistant and pandrug-resistant bacteria: an international expert proposal for interim standard definitions for acquired resistance. Clin Microbiol Infect 2012; 18: 268-81.

11. Barwell ND, Devers MC, Kennon B, et al. Diabetic foot infection: Antibiotic therapy and good practice recommendations. Int J Clin Pract 2017; 71: 10.1111/ijcp.13006.

12. Apelqvist J, Larsson J. What is the most effective way to reduce incidence of amputation in the diabetic foot? Diabetes Metab Res Rev 2000; 16: 75-83.

13. Baba M, Davis WA, Norman PE, Davis TM. Temporal changes in the prevalence and associates of diabetes-related lower extremity amputations in patients with type 2 diabetes: the Fremantle Diabetes Study. Cardiovasc Diabetol. 2015; 14: 1-10.

14. De Jesus-Silva SG, De Oliveira JP, Colepicolo Brianezi MH, De Moraes Silva MA, Krupa AE, Cardoso RS. Analysis of risk factors related to minor and major lower limb amputations at a tertiary hospital. J Vasc Bras 2017; 16: 16-22.

15. Namgoong S, Jung S, Han SK, Jeong SH, Dhong ES, Kim WK. Risk factors for major amputation in hospitalised diabetic foot patients. Int Wound J 2016; 13: 13-9.

16. Moon KC, Kim SB, Han SK, Jeong SH, Dhong ES. Risk factors for major amputation in hospitalized diabetic patients with forefoot ulcers. Diabetes Res Clin Pract 2019; 158: 107905.

17. Al-Mahroos F, Al-Roomi K. Diabetic neuropathy, foot ulceration, peripheral vascular disease and potential risk factors among patients with diabetes in Bahrain: a nationwide primary care diabetes clinicbased study. Ann Saudi Med 2007; 27: 25-31.

18. Bruun C, Siersma V, Guassora AD, Holstein P, de Fine Olivarius N. Amputations and foot ulcers in patients newly diagnosed with type 2 diabetes mellitus and observed for 19 years. The role of age, gender and co-morbidity. Diabet Med 2013; 30: 964-72.
19. Larsson LG, Baum J, Mudholkar GS. Hypermobility: features and differential incidence between the sexes. Arthritis Rheum 1987; 30: 1426-30.

20.Cheng YJ, Gregg EW, Kahn HS, Williams DE, De Rekeneire N, Narayan KM. Peripheral insensate neuropathy--a tall problem for US adults? Am J Epidemiol 2006; 164: 873-80.

21.Hjelm K, Nyberg P, Apelqvist J. Gender influences beliefs about health and illness in diabetic subjects with severe foot lesions. J Adv Nurs 2002; 40: 673-84.

22. Orneholm H, Apelqvist J, Larsson J, Eneroth M. High probability of healing without amputation of plantar forefoot ulcers in patients with diabetes. Wound Repair Regen 2015; 23: 922-31.

23. Al-Rubeaan K, Youssef AM, Ibrahim HM, et al. All-cause mortality and its risk factors among type 1 and type 2 diabetes mellitus in a country facing diabetes epidemic. Diabetes Res Clin Pract. 2016; 118: $130-9$

24. Boyko EJ, Ahroni JH, Stensel V, Forsberg RC, Davignon DR, Smith DG. A prospective study of risk factors for diabetic foot ulcer. The Seattle Diabetic Foot Study. Diabetes Care 1999; 22: 1036-42.

25. Shatnawi NJ, Al-Zoubi NA, Hawamdeh HM, Khader YS, Garaibeh $\mathrm{K}$, Heis HA. Predictors of major lower limb amputation in type 2 diabetic patients referred for hospital care with diabetic foot syndrome. Diabetes Metab Syndr Obes 2018; 11: 313-9.

26. Selvin E, Marinopoulos S, Berkenblit G, et al. Meta-analysis: glycosylated hemoglobin and cardiovascular disease in diabetes mellitus. Ann Intern Med 2004; 141: 421-31.

27. Winkley K, Stahl D, Chalder T, Edmonds ME, Ismail K. Risk factors associated with adverse outcomes in a population-based prospective cohort study of people with their first diabetic foot ulcer. J Diabetes Complications 2007; 21: 341-9.

28. Cardoso HC, Zara ALSA, Rosa SSRF, et al. Risk factors and diagnosis of diabetic foot ulceration in users of the Brazilian public health system. J Diabetes Res 2019; 2019: 5319892.

29. Namgoong S, Jung S, Han SK, Jeong SH, Dhong ES, Kim WK. Risk factors for major amputation in hospitalised diabetic foot patients. Int Wound J 2016; 13 Suppl 1: 13-9.

30. Al-Rubeaan K, Al Derwish M, Ouizi S, et al. Diabetic foot complications and their risk factors from a large retrospective cohort study. PLoS One 2015; 10: e0124446.

31. Khawaja N, Abu-Shennar J, Saleh M, Dahbour SS, Khader YS, Ajlouni KM. The prevalence and risk factors of peripheral neuropathy among patients with type 2 diabetes mellitus; the case of Jordan. Diabetol Metab Syndr 2018; 10: 8.

32. Faglia E. Characteristics of peripheral arterial disease and its relevance to the diabetic population. Int J Low Extrem Wounds 2011; 10: 152-66.

33. Bozkurt F, Tekin R, Celen MK, Celal A. Diyabetik ayak enfeksiyonlu hastalarda Wagner sınıflaması ve kültür sonuçlarının değerlendirilmesi. Dicle Tip Dergisi. 2011; 38: 31-4.

34. Oliveira AFD, Oliveira Filho HD. Microbiological species and antimicrobial resistance profile in patients with diabetic foot infections. J Vasc Bras 2014; 13: 289-93

35. Oliva A, Giacobbe DR, Di Luca M, Miller NS. New insights into infections due to multidrug resistant gram negative Bacteria: The Interplay between Lab and Clinic. Biomed Res Int 2018; 2018: 8905874 